IP Periodica Polytechnica Civil Engineering

\author{
60(1), pp. 83,88, 2016 \\ DOI: $10.3311 / P$ Pci.7899 \\ Creative Commons Attribution (1) \\ RESEARCH ARTICLE
}

\section{Ripening in Chemically Aggressive Environment the HPC Reinforced with Hybrid Steel Fiber}

Aldjia Boutiba, Rabah Chaid, Laurent Molez, Raoul Jauberthie

Received 10-01-2015, accepted 07-06-2015

\begin{abstract}
The high performance concretes reinforced with metallic fiber are used more and more in the construction. Under the current policy of sustainable development, these are the materials that procure gains of consequent mass, which can increase the durability of structures, which contributes to the reduction of the impact of cementitious materials the greenhouse effect. This study investigated the ripening of hybrid steel fiber reinforced high performance concrete, with $15 \%$ substitution of cement by blast furnace slag, in water sulphated and Rance-France seawater. This experimental study analysed the effect of 6 months of ripening of the simple, in chemically aggressive water, on the compactness and the microstructure of the cement matrix and the possible alteration of the metal fibers. The gotten results show no significant alteration or the cement matrix or fibers by water sulphated and seawater.
\end{abstract}

\section{Keywords \\ $H P C \cdot$ fiber $\cdot$ slag $\cdot$ durability}

\section{Aldjia Boutiba}

Unit of research: Materials - Processes and Environment Research Unit, University of Boumerdes, Boumerdes, Algeria

e-mail: boualdjedi@yahoo.fr

\section{Rabah Chaid}

Unit of research: Materials - Processes and Environment Research Unit, University of Boumerdes, Boumerdes, Algeria

e-mail: chaidr@yahoo.fr

\section{Laurent Molez}

Civil Engineering Materials and Mechanical Engineering Laboratory, INSARennes, France

e-mail: Laurent.molez@insa-rennes.fr

\section{Raoul Jauberthie}

Civil Engineering Materials and Mechanical Engineering Laboratory, INSARennes, France

e-mail: raoul.jauberthie@insa-rennes.fr

\section{Introduction}

The high performance concretes reinforced with metallic fiber are used more and more in the construction, when casting in situ on the work and prefabrication. The most important advantages are hindrance of macrocracks' development, delay in microcracks' propagation to macroscopic level and the improved ductility after microcracks' formation [1].

Under the current policy of sustainable development, including it's environmental and economic dimensions. This type of material acquires the mechanical resistances going from 20 to $30 \mathrm{MPa}$ in 24 hours, which can increase productivity and reduce construction time on site. It provides substantial gains mass, it is possible to build with less formwork, less concrete to set up and less frames than ordinary concrete. This has been shown for HPC and VHPC (gains of 25 to 40\%) [2-4].

The making of a HPC requires a cement content of $450 \mathrm{~kg} / \mathrm{m}^{3}$ average, considering the broadcasts of the $\mathrm{CO}_{2}$, the cements will be more and more expensive, in particular the cement without addition (CEM I). In this fact, the substitution of a quantity of cement, by slag in the composition of this type of concrete (HPC), permits greenhouse gas emissions limitation, In order to valorise the waste and to save the cement. Also, the hydration of slag does not produce portlandite, but consumes that produced during the hydration of cement [5]. The blast furnace slag improves the durability of concrete to sulphates by dilution aluminates and portlandite content reduction as well as increase of compactness of hydrates in connection with the reduction of the pore volume [6,7].

Factors influencing the durability of concrete may be internal to the concrete (porosity, permeability, diffusivity) or the external environments (wintry, chemically aggressive ...). Chemical factors are often the most important, since; they lead to the deterioration of the cement matrix by dissolution reactions and swelling hydrate. This promotes depassivation of metal fibers in concrete and then particularly their corrosion by chloride [8].

The presented work is achieved at the laboratory of civil engineering, mechanical engineering (materials) of INSA RennesFrance. It has for object the survey of the durability of high performance concretes reinforced with metallic fiber with substitu- 
tion of $15 \%$ of the cement by the blast furnace slag. The tests of characterization are about his compactness, his microstructure and the state of the metallic fibers. The dosage in slag optimized in previous studies is $15 \%$ (instead of cement). This content induces mechanical strength at 28 days very high [9]. For this study we adopted the site conditions often encountered in Algeria, that is to say, the study of concrete curing takes place in the gypsum water and seawater corrosive salts of seawater are substantially sulphates and chlorides.

\section{Materials and methods}

The materials used for making concrete study are:

\subsection{Cement}

Portland cement without mineral additives CEM I 52.5 PM ES CP2 of Lafarge France. The Chemical and mineralogical composition are shown in Table 1 Table 2 summarises physical and mechanicals characteristics of cement.

\subsection{Slag}

A blast furnace slag plant in El-Hajar-Annaba Algeria is an amorphous granular ground to a specific surface area greater than that of cement; whose chemical composition and physical characteristics are reported in Table 3

The particle size characteristics of the cement and slag measured by laser particle Cilas 1180 are shown in Fig. 1] The particle size of the slag is lower than that of cement CEM I. This confirms previous measures specific surface area.

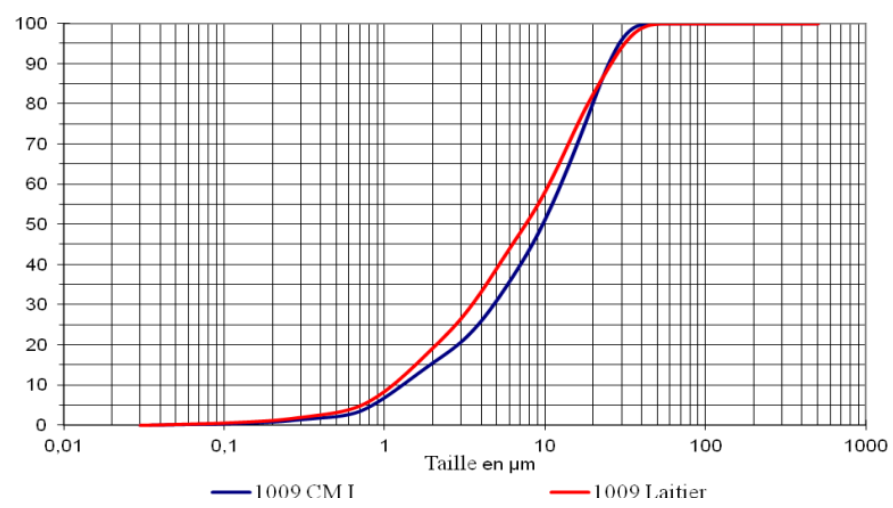

Fig. 1. Particle size distribution of cement and slag.

\subsection{Aggregates}

The aggregates used are: A flinty sand crushing $(0 / 2)$ of the sandpit and two fractions of flinty gravels crushing $(2 / 6)$ and $(6 / 12)$. Their physical properties are presented in Table 4.

\subsection{Admixture}

The admixture is a superplasticizer, Sika ViscoCrete TEMPO 9.

\subsection{Steel fibres}

We used a mixture of short fibres and fibres with end hooks (Dramix RC-80/50BN) shown in Figures 2 and 3 These fibres are added at ratio of $0.35 \%$ of volume per cubic meter of concrete.

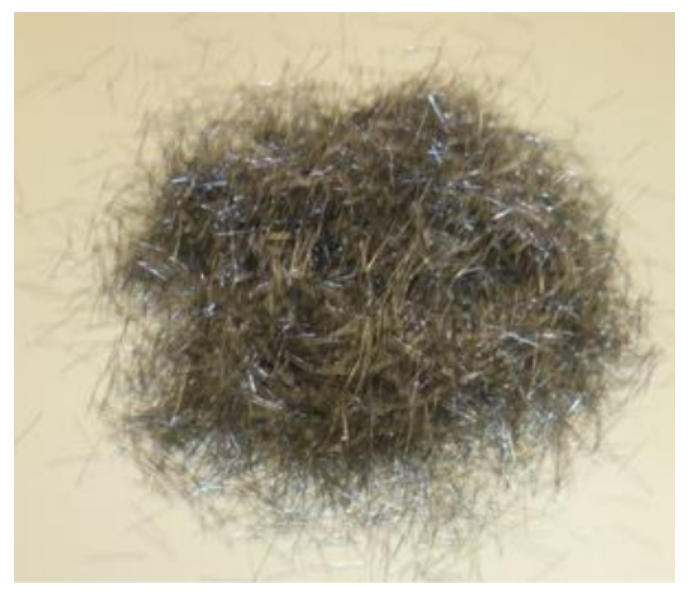

Fig. 2. Short fibres

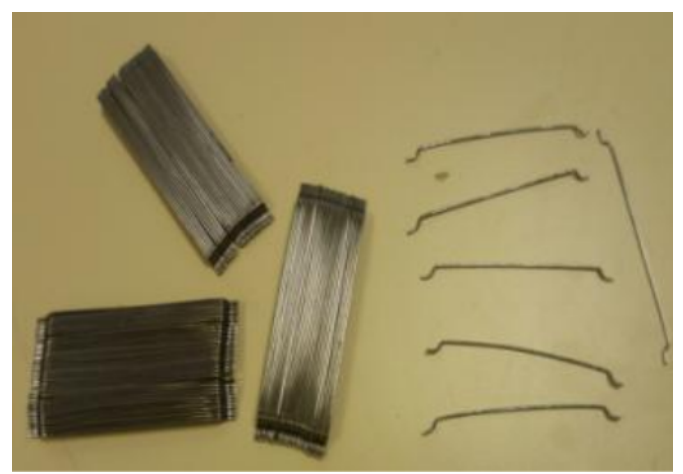

Fig. 3. Fibres with end hooks

The formulation of the concrete submitted to the tests (studied concrete) is achieved with the method of Dreux-Gorisse while using the software concrete lab free of the LCPC. After the tests of suitability, the composition of basis kept for these concretes is presented in Table 5

The specimens of the studied concretes (concrete with slag without fibre and concrete with slag and fibres) are placed, after demolding, in total immersion at a temperature of $20^{\circ} \mathrm{C}$, in the following mediums of conservation: drinking water, water selenitic (with 5\% gypsum), seawater of Rance-France. Table 6 summarizes the nomenclature of the concretes and the corresponding surroundings of conservation.

After 6 months of ripening, the test specimens are dried then placed in an air-conditioned room, where relative humidity is fixed to $50 \%$ and the temperature to $20^{\circ} \mathrm{C}$.

\section{Results and discussion}

3.1 Effect chemically aggressive environments on the mechanical properties

Figure 4 reflects the evolution of splitting strengths of the elaborate concretes ripened in the different surroundings of conservation. In the same way we presented the compressive strength in Figure 5, to estimate the effect of chemically aggressive environments on the mechanical performance of concrete study. 
Tab. 1. Chemical and mineralogical composition of cement used

\begin{tabular}{cccccccccccc}
\hline \multicolumn{2}{l}{ Elements $\mathrm{CaO}$} & $\mathrm{SiO}_{2}$ & $\mathrm{Al}_{2} \mathrm{O}_{3}$ & $\mathrm{Fe}_{2} \mathrm{O}_{3}$ & $\mathrm{MgO}$ & $\mathrm{K}_{2} \mathrm{O}$ & $\mathrm{Na}_{2} \mathrm{O}$ & $\mathrm{SO}_{3}$ & $\mathrm{RI}$ & $\mathrm{PAF}$ & $\mathrm{CaO}_{L}$ \\
\hline$\%$ & 66.60 & 22.40 & 2.96 & 2.33 & 0.95 & 0.15 & 0.10 & 2.13 & 0.20 & 1.59 & 0.50 \\
\hline Minerals & $\mathrm{C}_{3} \mathrm{~S}$ & & $\mathrm{C}_{2} \mathrm{~S}$ & & & $\mathrm{C}_{3} \mathrm{~A}$ & & & $\mathrm{C}_{4} \mathrm{AF}$ & \\
\hline$\%$ & $65.3 \%$ & & 18.6 & & & 4.35 & & & \\
\hline
\end{tabular}

Tab. 2. Physical and mechanical characteristics of cement used

\begin{tabular}{ccc}
\hline Physical characteristics & Initial setting time & $2 \mathrm{~h} 55 \mathrm{~min}$ \\
& Shrinkage at 28 days & $560 \mu \mathrm{m} / \mathrm{m}$ \\
& Density & $3.16 \mathrm{~g} / \mathrm{cm}^{3}$ \\
& Chemical stability & $0.5 \mathrm{~mm}$ \\
Mechanical characteristics & Specific surface area & $3590 \mathrm{~cm}^{2} / \mathrm{g}$ \\
& Age (days) & Compressive strength (MPa) \\
& 7 & 31.9 \\
& 28 & 49.11 \\
\end{tabular}

Tab. 3. Chemical composition and physical characteristics of slag

\begin{tabular}{ccccccccccc}
\hline Elements & $\mathrm{CaO}$ & $\mathrm{SiO}_{2}$ & $\mathrm{Al}_{2} \mathrm{O}_{3}$ & $\mathrm{Fe}_{2} \mathrm{O}_{3}$ & $\mathrm{MgO}$ & $\mathrm{K}_{2} \mathrm{O}$ & $\mathrm{Na}_{2} \mathrm{O}$ & $\mathrm{SO}_{3}$ & $\mathrm{RI}$ & $\mathrm{PAF}$ \\
\hline$\%$ & 39.77 & 41.69 & 7.05 & 1.41 & 5.49 & 0.44 & 0.10 & 0.15 & 0.12 & 0.11 \\
\hline \multicolumn{1}{l}{ Physical characteristics } & \multicolumn{3}{c}{ Density } & & $2.99 \mathrm{~g} / \mathrm{cm}^{3}$ & \\
& \multicolumn{4}{c}{ Specific surface area } & & $8500 \mathrm{~cm}^{2} / \mathrm{g}$. \\
\hline
\end{tabular}

Tab. 4. Physical properties of aggregates

\begin{tabular}{cccc}
\hline Types & Sand & Gravels 2/6,3 & Gravels 6/12 \\
$\begin{array}{c}\text { Actual density } \rho_{r}\left(\mathrm{Kg} / \mathrm{m}^{3}\right) \\
\text { Apparent density } \rho_{\text {app }}\end{array}$ & 2604,00 & 2620,00 & 2645,71 \\
$\left(\mathrm{Kg} / \mathrm{m}^{3}\right)$ & 1555,53 & 1365,63 & 1338,79 \\
\hline
\end{tabular}

Tab. 5. Concrete mixes

\begin{tabular}{cc}
\hline Constituents & Quantity $\left(\mathrm{kg} / \mathrm{m}^{3}\right)$ \\
\hline Cement & 446 \\
Slag & 66.9 \\
Gravel 6/12 & 891.9 \\
Gravel 2/6 & 85.2 \\
Sand 0/2 & 738.3 \\
Water & 155.6 \\
Admixtures & $0.34 \%$ of the weight of the cement \\
\hline
\end{tabular}

Tab. 6. The nomenclature of the concretes

\begin{tabular}{|c|c|}
\hline Concretes and surroundings of conservation & Denomination \\
\hline $\begin{array}{c}\text { Concrete with the slag and without fibers, kept in the } \\
\text { drinking water }\end{array}$ & CSDW \\
\hline $\begin{array}{c}\text { Concrete with the slag and without fibers, kept in the } \\
\text { seawater }\end{array}$ & cssw \\
\hline $\begin{array}{c}\text { Concrete with the slag and without fibers, kept in the } \\
\text { gypsum water }\end{array}$ & CSGW \\
\hline $\begin{array}{c}\text { Concrete fiber with addition of the slag, kept in the } \\
\text { drinking water }\end{array}$ & CFDW \\
\hline $\begin{array}{c}\text { Concrete fiber with addition of the slag, kept in the } \\
\text { seawater }\end{array}$ & CFSW \\
\hline $\begin{array}{c}\text { Concrete fiber with addition of the slag ,kept in the } \\
\text { gypsum water }\end{array}$ & CFGW \\
\hline
\end{tabular}


From the gotten results one can note that the difference of the resistances of the concretes kept in the water of faucet and those of the concretes kept in the seawater of and gypsum water is weak and sometimes same negligible.

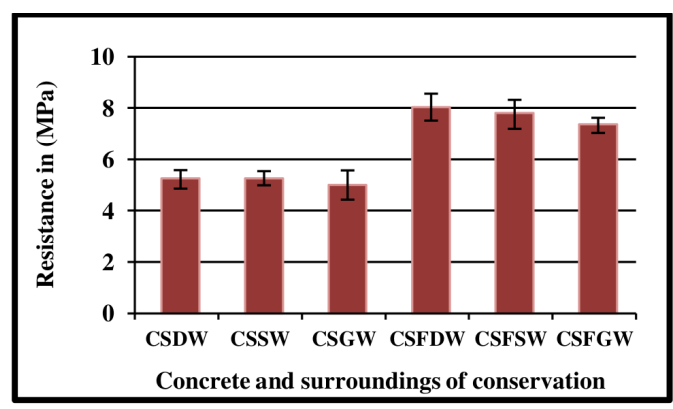

Fig. 4. Splitting strengths of the different concretes

We can think that the tested concretes resist to sulphates well and to the seawater. Therefore, there are not chemical reactions that entail falls of appreciable resistances. Also, the presence of the fibers entails a growth of the splitting strengths (Figure 4). But, slightly reduces the compressive strength (Figure 5).

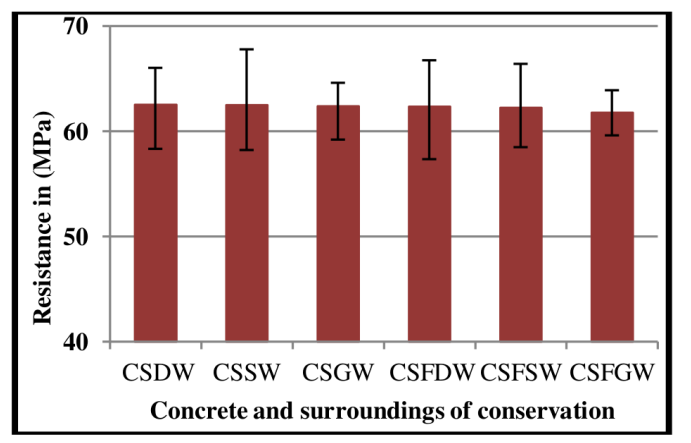

Fig. 5. Compressive strength of the different concretes

3.2 Effect chemically aggressive environments on the velocity of sound:

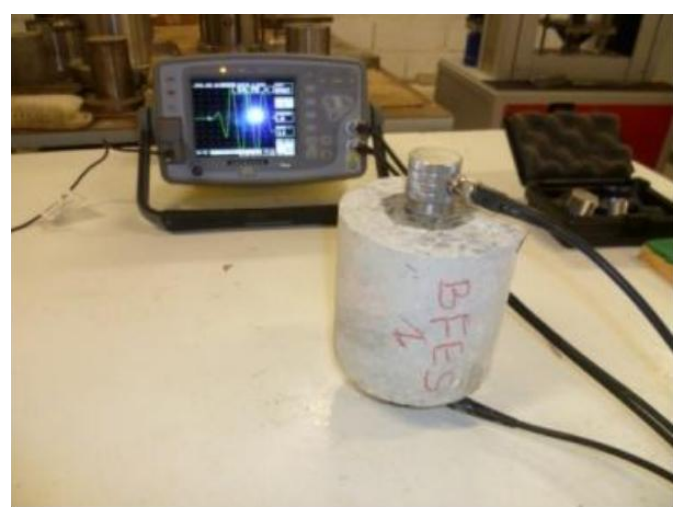

Fig. 6. Sound velocity test

This method consists in measuring the velocity of propagation of an ultrasonic wave through the concretes. According to, the state of the material, the waves change speed, the propagation of the waves is disrupted by discontinuities. When, the specimen contains the pores or cracks, the deterioration in the material increases and the velocity of propagation of the wave decreases.

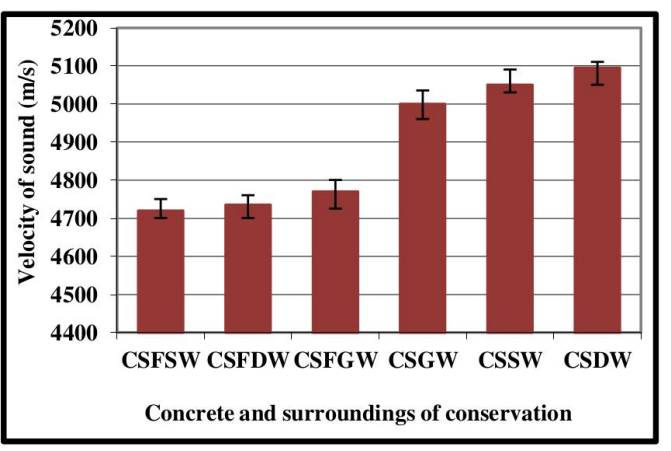

Fig. 7. Velocity of propagation of the sound through the concretes.

Figure 7 shows the velocity of propagation of sound waves of concrete in different surroundings of conservation. The values of the velocity are important and homogeneous between the different surroundings for a same type of concrete. Also, the velocity is more important for fiber concrete for the presence of steel reinforcement.

\subsection{Effect chemically aggressive environments on the wa- ter porosity and apparent density}

The method used is the AFREM recommendation entitled (Determination of apparent density and pore system accessible to water) [10]. The results of these tests are shown in Figures 8 and 9 . There is a very small difference in porosity concretes stored in drinking water and those stored in the gypsum water and seawater; this proves the good performance of concrete studies in the chemically aggressive environments.

The porosity of concretes reinforced with metallic fibre is more important than those of concrete without fibres. It is commonly accepted that the inclusion of fibers in a HPC led to a decline of compactness related to the reduction of the rheological properties [11].

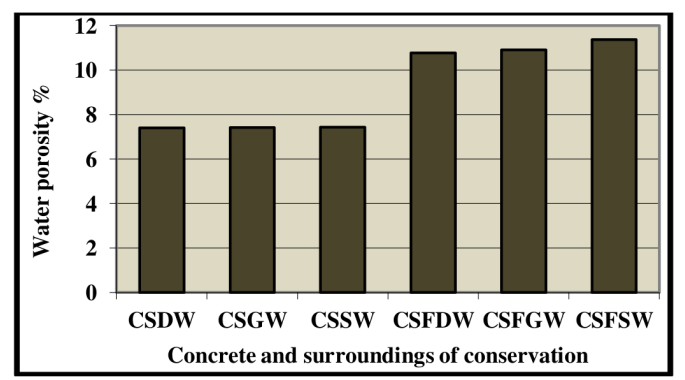

Fig. 8. Water porosity of the different concretes

Indifferently of the conservation middle, the apparent density increases with the reduction of the porosity accessible to the water; it is verified for the two concretes types.

\subsection{Effect chemically aggressive environments on the ab- sorptivity of water by capillarity:}

The capillary water absorption is an important phenomenon for the durability of concrete, by the fact that the penetration of water into the concrete vehicle with her aggressive ions that can cause impaired cement matrix subsequently corrosion steel 


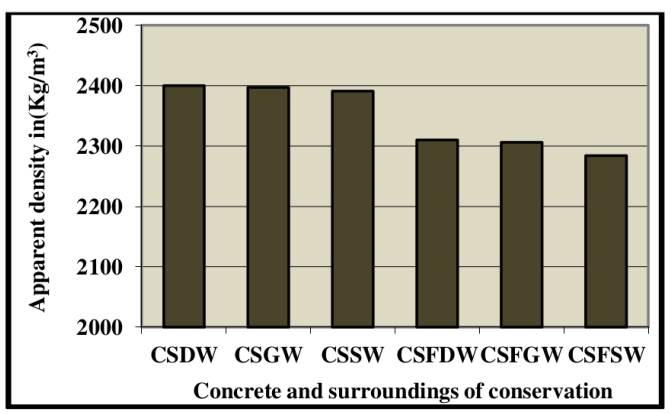

Fig. 9. Apparent density of the different concretes

reinforcement in reinforced concrete.

The test of water absorption by capillarity involves placing the lower surface of the specimen (bottom of the mould) to the contact of water and to follow according to the time, the evolution of the mass. Figure 10 illustrates the evolution of water absorption by capillarity of the survey concretes according to the time.

The gotten results show that in the first hours of the test (up to 8 hours), the capillary coefficients of absorption of the concretes fibers and non fibers are globally similar for the three surroundings of conservation. But after 24 hours, the concrete with and without fiber preserved in seawater have a slightly higher absorption than those kept in drinking and gypsum water.

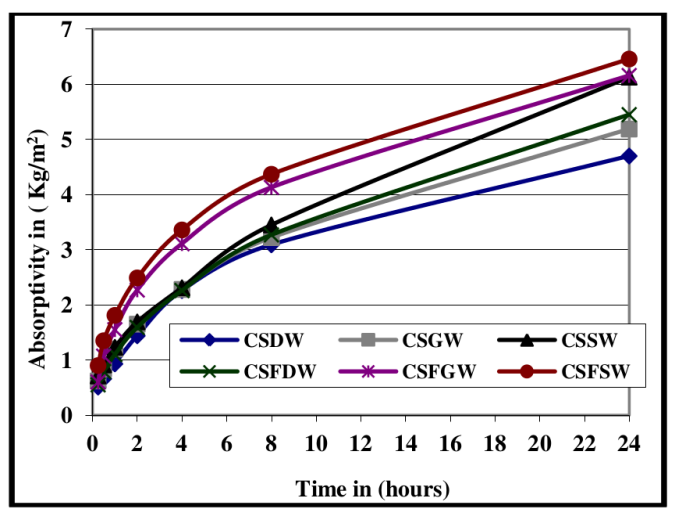

Fig. 10. Absorption capillary coefficients of the different concretes

\subsection{The state of the surface of the specimens examined in a scanning electron microscopy}

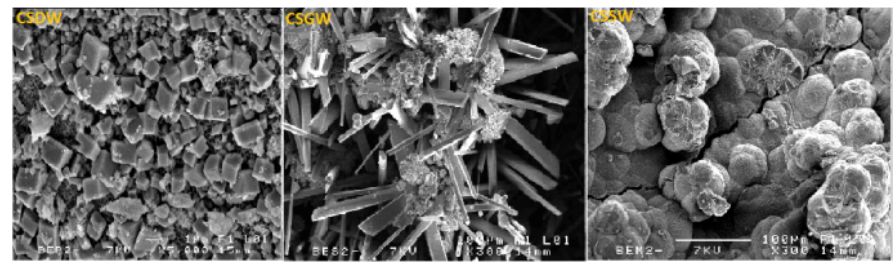

Fig. 11. Micrographs of HPC after ripening in different environments

Figure 11 shows the micrographs of the surfaces of concrete kept in different environments. The concrete stored in drinking water (CDW), shows the presence of carbonates that crystallize in cubic inclined, for concrete stored in water gypsum (CGW), the gypsum crystallizes in a hexagonal shape. However, the sur- faces of concrete stored in seawater (CSW), are covered with brucite $[\mathrm{Mg}(\mathrm{OH}) 2]$ in the form of mushrooms.

\subsection{The state of the fibers in the three environments}

The state of the fibers for the three environments is virtually identical (figure12); we do not see any particular difference. It can be concluded that the fibers are not altered, it proves that the concrete is not affected very sensitive ways, nor by the gypsum water, nor by the seawater. This explains the results of the mechanical performance, porosity and apparent density discussed previously.

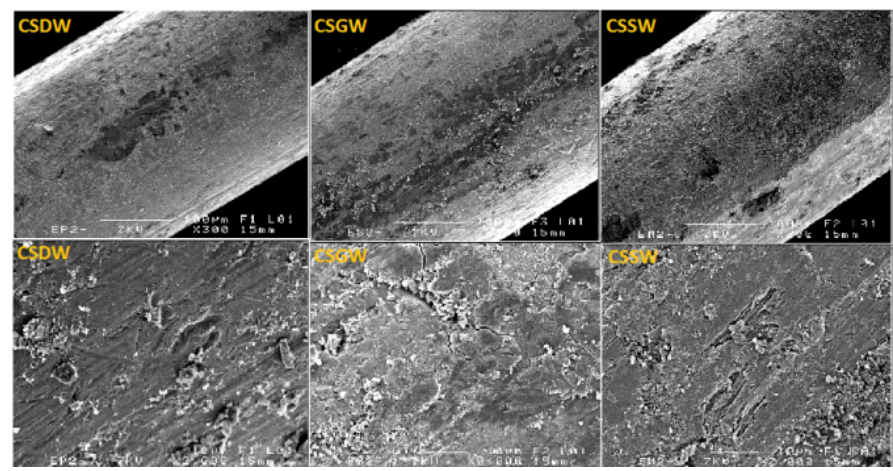

Fig. 12. SEM observation of the surface fibers for three environments

\section{Conclusions}

This survey permits to put in evidence the effect gypsum water and the seawater SFRHPC. Our findings are as fallout:

The difference between the resistance of concrete stored in drinking water and those stored in the gypsum water and sea water is low and even negligible. Also, the presence of fibers reduces the compressive strength, but causes an increase in splitting strengths.

The values of the velocity of propagation of ultrasonic waves are important and homogeneous between the different surroundings for a same type of concrete.

There is a very slight difference between the densities and porosities of concrete stored in water and those stored in the selenide water and seawater

One notes a very weak difference between the apparent density and the porosity of the concretes kept in the drinking water and those kept in gypsum water and the seawater.

After 24 hours, the bundles and not kept in seawater concretes greater than those kept in tap water and water selenide water absorption.

After 24 hours, the concretes with fiber and without fiber, kept in the seawater, present more important water absorption than those kept in the drinking water and the gypsum water.

The micrographs of the external microstructure of the cement matrix are identical to those of healthy concrete, that is to say, do not reveal expansion or alteration of hydrates.

The state of the fibers for the three surroundings is almost identical, it sees no particular difference. So the fibers are not altered. 


\section{Acknowledgement}

The study was performed with the financial support of the French-Algerian research collaboration (CMEP-Tassili) between the laboratory of materials, procedures and environments of the University of Boumerdes in Algeria and the civil and mechanical engineering laboratory of INSA-Rennes in France. The authors would like to thank EGIDE and we would like to acknowledge Francis Gouttefangeas engineer cmEBA for his contribution in the analysis and electron microscopy observations.

\section{References}

1 Holschemacher K, Mueller T, Ribakov Y, Effect of steel fibers on mechanical properties of high-strength concrete, Materials and design, 31, (2010), 2604-2615, DOI $10.1016 / \mathrm{j}$. matdes.2009.11.025

2 Aitcin PC, Concretes high performance, Eyrolles; France, 2001.

3 Escadeillas G, The eco-materials in the construction: stakes and perspectives, the French-speaking Regrouping for research and the formation on the concrete (RF)2B 2006, In:; Toulouse, France, 2006-06-19, www-lmdc. insa-toulouse.fr/.../\%25pdf-Escadeillas.pdf

4 Zea Escamilla E, Habert G, Environmental impacts of bamboobased construction materials representing global production diversity, Journal of Cleaner Production, 69, (2014), 117-127, DOI 10.1016/j.jclepro.2014.01.067

5 Tsai WH, Lin SJ, Liu JY, Lin WR, Lee KC, Incorporating life cycle assessments into building project decision-making: An energy consumption and CO2 emission perspective, Journal of Cleaner Production, 36, (2011), 30223029, DOI 10.1016/j.energy.2011.02.046

6 Quenee B, Martinet G, LERM INFOS n19, sulfur, Laboratory of study and search for materials LERM, 2010, http://doc. lerm. fr/2010/12/

7 Divet L, How to protect of the reactions sulfatique in the concretes, Bulletin of the laboratories of the bridges and pavements, 240, (2002), 87-94.

8 Cohen MD, Mather B, Sulfate attack on concrete-Research needs, ACI Materials Journal, 24(1), (1991), 177-202.

9 Chaid R, Formulation, characterization and durability of the BHP to the additions local cimentious, $\mathrm{PhD}$ thesis, polytechnic national School; Algiers, Algeria, 2006.

10 Arliguie G, Hormain $\mathbf{H}$, Recommendation AFREM ConcretesDetermination of apparent density and pore system accessible to water, In: GranDuBé, press the ENPC; Paris-France, 2007, pp. 381-385.

11 Ladaoui W, Experimental Survey of the long-term behavior of the BHP destined to the works of storage of the radioactive garbage, $\mathrm{PhD}$ thesis, University of Toulouse III-Paul Sabatier 2; Toulouse, France, 2010. 